\title{
Mapping research areas and collaboration in the College of Human Sciences, University of South Africa
}

\author{
Omwoyo Bosire Onyancha' \\ University of South Africa, Department of Information Science, PO Box 392 UNISA 0003 \\ onyanob@unisa.ac.za
}

\begin{abstract}
This paper examines the research output of the College of Human Sciences (CHS) at the University of South Africa (UNISA) with a view to determining the subjects or topics of research focus as well as the pattern and extent of research collaboration within the college. Using informetric approaches and more specifically the content analysis, the study employs various analytical technologies including UCINET for Windows, Microsoft Excel, Pajek, TI and TextStat to analyse data that was extracted from the University's institutional research management system (IRMA). Results indicate that the research focus of the college is largely on HIVIAIDS; the most productive department was Christian Spirituality; the actual research output of the college is below the expected output; research is largely conducted singly as opposed to collaborative research; and that external research collaboration is common. Conclusions and recommendations for further research are provided.
\end{abstract}

\section{Introduction}

Various bibliometric indicators have been proposed for purposes of evaluating the research performance of individuals, organisations and even countries. The application of these indicators in research evaluation has been widely published in different publication types including journals (e.g. Journal of Informetrics, Scientometrics journal, and the Journal of the American Society for Information Science), newspapers, and books as well as on the Internet. Publications count, patents count and citation count and impact, among other informetric measurements, are the commonly applied indicators in measuring the performance of individuals, journals, institutions and countries in research (Jacobs, 2002; Onyancha, 2008; Onyancha \& Ocholla, 2009). There is, however, contestation as to which method is the most appropriate in measuring research performance especially at the individual level (Onyancha, 2008). Is it peer-review, bibliometrics/informetrics, economic rate of return, case studies, retrospective analysis or questionnaire surveys? As Onyancha (2008) notes, none of these approaches or methods is foolproof. Each has its strengths and weaknesses.

Nevertheless, publications count and analysis is increasingly becoming recognised worldwide as the measurement indicator of research output and therefore an individual's performance in research. Publications count is used to study publication or research output in different countries, the amount produced during different periods, or the amount produced in different subdivisions of the field (Hertzel, 1987; Sengupta, 1992). Nicholas \& Ritchie (1978) observe that studies using publications count normally describe the characteristics or features of literature. A study conducted on 4,000 researchers, to identify appropriate bibliometric indicators for research performance measurement in their disciplines, found that publications (i.e. publication of research results in refereed journals) ranked as the most important performance indicator (Kostoff, 200I). Other performance indicators, according to the same study, include peer reviewed books, keynote addresses, conference proceedings, citation impact, chapters in books, and competitive grants.

According to Victoria (n.d.), publications count is the simplest informetric measurement. Hence in its simplest form, publications count involves counting the number of papers, citations, references, patent citations, words within a text, books and other writings in the field, or often by a count of those writings which have been abstracted in a specialised abstracting journal. Such counts provide a general view of the production activity in a field, institution or company as well as highlighting an individual's performance. Examples of questions that publications count is designed to answer are:

I.How many publications, citations, books, patents, etc. has a particular author, group of authors, institutions and/or countries/geographic regions produced?

2.How much has been produced on a given topical issue, discipline, country, regional area, etc?

3.How many publications have each been authored by how many authors?

4.How many publications were published in a given source (journal, magazine, etc?)

5.In how many languages are documents published?

6. How often does a particular word appear in a text?

I. Omwayo Bosire Onyancha, $\mathrm{PhD}$, is an Associate Professor in the Department of Information Science at the University of South Africa. 
Although commonly applied in assessing research output, publications count should be used cautiously, particularly when used as a proxy of research productivity because of the limitations associated with it. Objections have been raised in the following areas as outlined in King (1987:262) and Kostoff (200I, Section IV-B-5-ii, para. I):

I.Publications count does not provide any indication as to the quality of the work performed.

2.Informal and formal non-journal methods of communication in science are ignored.

3.Publication practices vary across fields and between journals.

4.Social and political pressures on a group to publish vary according to country, to the publication practices of the employing institution, and the emphasis placed on the number of publications for obtaining tenure, promotion, grants, etc.

5.The choice of the appropriate database is problematic and therefore makes it very difficult to retrieve all the papers for a particular field.

6. An awareness of the use of publications count for assessment may encourage undesirable publishing practices such as the production of very brief papers.

7.Very few active researchers produce heavily cited papers.

8.Biases favouring publications of established authors.

Despite all these shortcomings, publications count still remains a valuable tool for information and other social scientists interested in measuring research productivity. A few, if not all, of the aforementioned drawbacks in the use of publications count could, however, be resolved if the method was used together with citation analysis.

Besides the assessment of the number of publications produced by a given entity (journal, author, database, country, institution, etc.), at both the individual and corporate level, analysts are increasingly becoming interested in ' $w$ hat' is being researched. In other words, which are the areas or topics most researched and/or published? Most applications of bibliometric techniques have focused on finding out the most productive authors, institutions, journals and even countries. As a result, content analysis of the publications, which was previously not done, is gaining popularity among research analysts and decision makers as a way of determining the areas of research focus. According to Macias-Chapula, Sotolongo-Aguilar, Magde \& Solorio-Lagunas (1999:565), subject content analysis of AIDS literature would mirror 'not only the construction of [a] field by specific institutions and countries, but also what happens to subject access as the knowledge base and environment of a discipline grow and change'. Kizito (2002) argues that content analysis can be used to 'find out what prominence is given to a specific area of reporting'. The method can also be used to determine the inter-, trans- and multi-disciplinarity research. Results from content analysis can also reflect areas of research collaboration.

\section{Research at the College of Human Sciences}

The College of Human Sciences (hereafter referred to as CHS or simply as the College) considers research as a vital component of its mandate, besides tuition, academic citizenship and community engagement. In line with its mission of being an African university in service of humanity, UNISA's research vision is to create a vibrant research culture that emphasises relevant and responsive research and contributes positively to the development of Africa. Towards that vision, UNISA seeks to increase innovative research and research capacity by (a) inculcating multidisciplinary, interdisciplinary and transdisciplinary (MIT) research, epistemologies, methods, and programmes; (b) cultivating Open and Distance Learning (ODL) research; and (c) sustaining a supportive, enabling and research environment (UNISA, 2010). In view of these three broad strategies specific to research, the CHS through the office of the Deputy Executive Dean, Research, has embarked on an aggressive programme of sensitising the academic staff on the need for conducting research while discharging their responsibilities and duties as academics. As a result, the College has developed a strategic plan that is intended to improve the research portfolio of the College. The plan spells out research activities, performance measures, targets to be achieved, and the persons or offices responsible for the implementation of the activities.

Administratively, the management (i.e. planning, coordinating and setting the research agenda, among others) of research within the CHS fall under the portfolio of the Deputy Executive Dean, Research. Policies and research plans are drawn by this office in collaboration with the College Research Committee (CRC) which comprises School Directors (or their nominees) and one representative from each department within the College. The College comprises 27 departments which fall into four schools, namely: School of Arts (10), School of Education (4), School of Humanities and Theology (12) and the School for Graduate Studies (I). The college offers over 350 qualifications covering a variety of study areas which form or could form the focus areas of research.

\section{Methods and materials}

The University of South Africa has put in place an electronic system that is used to capture details of publications by its community that includes teaching staff and administrative staff. The system, known as University Office Package for

Inkanyiso, Jnl Hum \& Soc Sci 2010, 2(2) 
institutional research management (IRMA), captures such information as the type of document being captured, year of publication, Department of Education (DoE) reporting year, publication title, number of internal UNISA authors, number of external authors, journal name, volume and issue number of journal, number of pages of the publication, author's departmental affiliation, etc. The types of publications and research activities captured in the system are articles, book chapters, books, conference attendance, conference proceedings, music and art, poster presentations, reviews, and scientific papers delivered at different forums. The system is also used to manage grants and generate reports. Reports can be filtered by institution, school, department, research output, research output category, author, and calculation. Once the data has been captured, it is verified and audited to ensure that the submitted publications conform to the DoE requirements. The Research Directorate office then forwards the submitted publication details to the DoE for subsidy determination and allocation.

The University of South Africa migrated to the current research management system in 2008. By the time of conducting this study, only publications of 2008 had been captured in the newly installed system. Plans are, however, underway to expand this study to include publications published before and after 2008 as their data is made available. According to Francette Myburg, the ICT technician in charge of managing the IRMA, the system is likely to be replaced soon with a more robust one which can allow searches for specific data, e.g. topics of research focus. The present system does not allow searches to be conducted; therefore it is not possible to identify, for example, the most commonly researched topics and, by extension, the trend of research on a given topic. This limitation can, however, be overcome by the use of informetric techniques and methods, e.g. content analysis approaches and techniques.

This study employed a content analysis of titles of publications produced by the CHS staff and captured in the IRMA system in 2008. Relevant data was extracted by filtering the records by 'college' and DoE year of reporting. All types of captured records that met the DoE requirements for subsidy allocation were included in the final analysis. Once the relevant information (e.g. author, document type, number of internal UNISA authors, number of external authors, department, title, names of authors, and journal name) was obtained, the data was saved in an Excel worksheet. Data analysis was done using various computer software which included Microsoft Excel, TI, TextStat, UCINET for Windows and Pajek. Microsoft Excel was employed to compute the number of publications and the DoE score per department. TI is software that generates a word-occurrence matrix and a normalised co-occurrence matrix from a set of lines (e.g., titles) and a word list and is used to identify relationships that exist among the words in a given list. In this study, we used $\mathrm{TI}$ to generate a list of the most commonly used title words and subjected this list to analysis in order to generate a normalised co-occurrence matrix which yielded strengths of association among the said words. UCINET's core/ periphery model was then performed on the co-occurrence matrix in order to determine the title words that form the core of research within the CHS (see Figurel). According to Borgatti \& Everett (1999) and Borgatti, Everett \& Freeman (2002), the core/periphery function simultaneously fits a core/periphery model to the data network, and identifies which actors (in this case, the title words) belong in the core and which belong in the periphery. The Pajek software is freely available for academic use and is used to generate, analyse and visualise large networks of institutions, people, words, countries, transport actors, etc. In this study, Pajek was used to generate the network of words as shown in Figure 2 . The textSTAT software 'makes text statistics, counts characters, words, and sentences to find words repetitions and how many times they appear in a given text' (see http://textstat.software.informer.com/). The frequency counts of words' appearances within the titles were generated using TextStat and presented in Table 4.

\section{Results}

This section presents and discusses the findings of the study under the following sub-headings:

- Number of publications per department

- Most common terms in article titles

- Core/periphery model of title terms

- Social map of most commonly used title terms

- Research collaboration at the CHS.

\subsection{Number of publications per department}

Table I provides the number and type of publications that were published in the CHS in 2008 and the Department of Education's (DoE) score for each department. The contents of Table I are sorted according to the DoE score. The Table reveals that the majority of the publications in 2008 were journal articles, which totalled 263 followed by chapters in books (18), papers in conference proceedings (13) and finally, books (2). Going by the DoE's assessment of different types of publications whereby a journal article is allocated one (I) unit, a paper in peer-reviewed conference proceedings receives one half $(\mathrm{I} / 2)$ of a unit, a book or chapter in a book on a subject is allocated 5 units (depending on several criteria as stipulated in the Policy and Procedures for the Measurement of Research Output of Public Higher Education Institutions - 
Republic of South Africa. Ministry of Education, $\left.2003^{2}\right)$, then the research output of the CHS, in terms of DoE units, was as follows: journal articles (263), chapters in books (90), conference proceedings (6.5) and books (2).

Table I Number of publications per department

\begin{tabular}{|c|c|c|c|c|c|c|}
\hline \multirow[t]{2}{*}{ Department } & \multicolumn{4}{|c|}{ Publications } & \multirow[t]{2}{*}{ Total items } & \multirow[t]{2}{*}{ DoE score* } \\
\hline & Articles & Books & Chaps in books & Conf proceeds & & \\
\hline Christian spirituality & 27 & & 2 & I & 30 & 26.50 \\
\hline English studies & 23 & & 1 & & 24 & 24.33 \\
\hline Old Testament & 22 & & & I & 23 & 22.00 \\
\hline New Testament & 18 & 1 & & & 19 & 19.00 \\
\hline Health studies & 20 & & & & 20 & 16.22 \\
\hline Communication science & 10 & & I & 2 & 13 & 15.33 \\
\hline Classics & 6 & & 2 & & 8 & 15.00 \\
\hline Teacher education & 17 & & 1 & 1 & 19 & 14.44 \\
\hline Human sciences & 3 & & 2 & & 5 & 13.00 \\
\hline Archaeology & 9 & & 2 & 2 & 13 & 12.98 \\
\hline Educational studies & 17 & & & I & 18 & 12.86 \\
\hline History & 7 & & 2 & & 9 & 12.16 \\
\hline Music \& Art & 11 & & & & 11 & 10.50 \\
\hline Philosophy & 5 & & 1 & I & 7 & 10.25 \\
\hline Graduate studies & 12 & 1 & & & 13 & 10.08 \\
\hline Systematic theology & 5 & & 1 & & 6 & 10.00 \\
\hline Linguistics & 11 & & & I & 12 & 9.62 \\
\hline African languages & 8 & & 1 & 2 & 11 & 9.57 \\
\hline Religious studies \& Arabic & 4 & & 1 & & 5 & 9.00 \\
\hline Psychology & 8 & & & I & 9 & 6.86 \\
\hline Information science & 9 & & & & 9 & 6.24 \\
\hline School of humanities & & & I & & I & 5.00 \\
\hline Political science & 4 & & & & 4 & 4.00 \\
\hline Sociology & 3 & & & & 3 & 2.00 \\
\hline Social work & 2 & & & & 2 & 1.50 \\
\hline Development studies & I & & & & I & 1.00 \\
\hline School of Arts & 1 & & & & I & 1.00 \\
\hline Total & 263 & 2 & 18 & 13 & 296 & 300.44 \\
\hline
\end{tabular}

* The DoE score refers to the units allocated to specific types of research outputs by the South African government's Department of

Education. The last column in Table I indicates the total number of units generated by each department.

With regard to departmental research output, the Department of Christian Spirituality led with a total of 30 publications which amounted to 26.50 units. The Department published a total of 27 journal articles, 2 chapters in books and one

2. "A book may be subsidised to a maximum of 5 units or portion thereof, based on the number of pages being claimed relative to the total number of pages of the book, if all the authors are affiliated to the claiming institution. A guideline of a minimum of 60 pages, and maximum of 300 pages will be allocated per unit or proportions and multiples thereof, if all the authors are affiliated to the claiming institution. However, where authors are affiliated with two or more institutions, the subsidy is shared between the claiming institutions" (Republic of South Africa. Ministry of Education, 2003:8).

Inkanyiso, Jnl Hum \& Soc Sci 2010, 2(2) 
paper in conference proceedings. Other departments that performed well include English Studies, Old Testament, New Testament, Health Studies, Communication Science, Classics, and Teacher Education. The total research output per department is, however, a partial measurement indicator of performance, as it does not take into account the output per capita. For example, a small department (with few academic staff members) may be seen as being unproductive when compared to big departments which may boast a large number of academic staff, a situation that may demand an assessment of departmental research output based on the average number of publications per academic staff.

Table 22008 expected research outputs per category of teaching staff

\begin{tabular}{|l|c|c|c|c|}
\hline & & \multicolumn{3}{|c|}{ Expected research output per person } \\
\hline & No of staff & Per 5 yrs & Per year & TOTAL \\
\hline Professor & 98 & 7 & 1.4 & 137.2 \\
\hline Associate Professor & 77 & 6 & 1.2 & 92.4 \\
\hline Senior Lecturer & 137 & 5 & 1.0 & 137.0 \\
\hline Lecturer & 123 & 4 & 0.8 & 98.4 \\
\hline Junior Lecturer & 19 & 3 & 0.6 & 11.4 \\
\hline Total & $\mathbf{4 5 4}$ & & & $\mathbf{4 7 6 . 4}$ \\
\hline
\end{tabular}

Table 3 CHS' academic staff

\begin{tabular}{|l|l|}
\hline Position Title & Total \\
\hline Academic Head of Department & 3 \\
\hline Assistant Curator & 1 \\
\hline Associate Professor & 77 \\
\hline Chair: NRF & 1 \\
\hline Executive Dean College of Human Sciences & 1 \\
\hline Junior Lecturer & 19 \\
\hline Junior Researcher & 1 \\
\hline Lecturer & 123 \\
\hline Professor & 98 \\
\hline Research Director & 3 \\
\hline Researcher & 1 \\
\hline Senior Lecturer & 137 \\
\hline Senior Researcher & 4 \\
\hline Grand Total & 469 \\
\hline
\end{tabular}

What was the expected research output of the CHS in 2008? Paragraph 8.3 of UNISA's Research Policy (UNISA, 2006) on research measurement and benchmarking outlines the expected research outputs of various categories of researchers within a five year period as shown in column three of Table 2, thus: Professor (7); Associate Professor (6); Senior Lecturer (5); Lecturer (4); and Junior Lecturer (3). On average, therefore, the expected research outputs (in units) for each category per year would be as follows: Professor ( I.4); Associate Professor (I.2); Senior Lecturer ( I.0); Lecturer (0.8); and Junior Lecturer (0.6). Assuming that all the teaching staff as outlined above were involved in research in 2008 and met the benchmarked outputs in the year, the expected total research outputs for each group would have been as follows: Professors (137.2), Associate Professors (92.4), Senior Lecturers (137), Lecturers (98.4), and Junior Lecturers (I I.4); which translates to a grand total of 476.4. It should be noted that this figure excludes research outputs of the other categories of academic staff (such as Chairs of Departments and other researchers) and administrative staff included in 
Table 3. By implication, the total research outputs of the CHS would be higher if all potential researchers met the threshold requirements.

Table 4 Most commonly used terms in titles of publications produced in the CHS, 2008

\begin{tabular}{|c|c|c|c|c|c|c|c|}
\hline TITLE TERM & HITS & TITLE TERM & HITS & TITLE TERM & HITS & TITLE TERM & HITS \\
\hline SOUTH & 37 & EVALUATION & 5 & CARE & 3 & POLITICS & 3 \\
\hline AFRICAN & 33 & EXPERIENCES & 5 & COMMUNITY-BASED & 3 & POVERTY & 3 \\
\hline AFRICA & 29 & GENDER & 5 & ENVIRONMENTAL & 3 & PRACTICE & 3 \\
\hline EDUCATION & 12 & HIGHER & 5 & ETHIOPIA & 3 & PRESENT & 3 \\
\hline AIDS & II & INVESTIGATION & 5 & GENOCIDE & 3 & PRIMARY & 3 \\
\hline HIV & 11 & JESUS & 5 & HEALTH & 3 & PRIVATE & 3 \\
\hline NURSES & 10 & LEARNING & 5 & HOSPITALS & 3 & PROFESSIONAL & 3 \\
\hline SCHOOL & 9 & SELECTED & 5 & HUNTER-GATHERER & 3 & PROVINCE & 3 \\
\hline SOUTHERN & 9 & TEACHERS & 5 & IDENTITY & 3 & RACISM & 3 \\
\hline SCHOOLS & 8 & WORLD & 5 & IMPACT & 3 & REFERENCE & 3 \\
\hline STUDY & 8 & CHRISTIAN & 4 & INFLUENCE & 3 & ROLE & 3 \\
\hline CASE & 7 & CULTURAL & 4 & INFORMATION & 3 & RURAL & 3 \\
\hline DEVELOPMENT & 7 & ENGLISH & 4 & INSTITUTIONS & 3 & SATISFACTION & 3 \\
\hline HUMAN & 7 & ETHICS & 4 & JOB & 3 & SECURITY & 3 \\
\hline LANGUAGE & 7 & FEMINIST & 4 & JUSTICE & 3 & SOCIAL & 3 \\
\hline MUSIC & 7 & IDENTITIES & 4 & LESOTHO & 3 & THEOLOGY & 3 \\
\hline RESEARCH & 7 & $\mathrm{JOHN}$ & 4 & MANAGEMENT & 3 & TIME & 3 \\
\hline ART & 6 & LEARNERS & 4 & NATAL & 3 & TRAINING & 3 \\
\hline LITERATURE & 6 & LITERACY & 4 & NEED & 3 & UNIVERSITY & 3 \\
\hline READING & 6 & MISSION & 4 & OLD & 3 & ZIMBABWEAN & 3 \\
\hline SPIRITUALITY & 6 & STUDENTS & 4 & PATTERNS & 3 & ZULU & 3 \\
\hline STATE & 6 & WAR & 4 & PERCEPTIONS & 3 & ACADEMIC & 2 \\
\hline $\mathrm{CHURCH}$ & 5 & WOMEN & 4 & PERSPECTIVE & 3 & ADOLESCENTS & 2 \\
\hline EARLY & 5 & ZIMBABWE & 4 & PHILOSOPHICAL & 3 & AFRICANS & 2 \\
\hline EASTERN & 5 & BLACK & 3 & PHILOSOPHY & 3 & AGE & 2 \\
\hline
\end{tabular}

\subsection{Most common terms in article titles}

Various authors as cited in Onyancha \& Ocholla (2009:4) have noted that titles of publications are 'very important components of any scientific or scholarly article as they form part of the access points in search and retrieval processes'. Yitzhaki in Onyancha \& Ocholla (2009:5) observes that: 'many information retrieval systems depend heavily on indexing by automated, computerised selection of words from article titles'. Informative titles of publications are therefore usually meant to reflect the focus areas or topics discussed in the publication and, by extension, the topics of research. The frequency of occurrence of the top 100 title words of published documents emanating from the CHS in 2008 is provided in Table 4. Among the most common title words in the order of decreasing frequency are: South (37), African (33), Africa (29), Education (I2), AIDS (II), HIV (II) and Nurses (I0), just to name those words that occurred I0 or more times in 
the CHS publications of 2008. According to Table 4, Education and HIV/AIDS are the key areas of research in the CHS, although as the core/periphery model in Figure I reveals, HIV/AIDS is the core research topic. One other finding that is worth mentioning is the frequent occurrence of the words case and study in the publication titles. This may mean that most of the researches conducted in the CHS are case studies and, therefore, reflect the most preferred method of research, i.e. case study.

\subsection{Core/periphery model of the most common title terms}

The core/periphery model illustrated in Figure I reveals the terms that were core or the nuclei of research in the College and those that were less researched and, therefore, comprised the periphery. The core terms include South, African, Africa, AIDS, HIV, Southern, and Eastern. The core research topic within the CHS in 2008 is thus HIV/AIDS contextualised within Southern and/or Eastern Africa. Among the title words that were in the periphery are Education, Nurses, School(s), Study, Case, Human, Language, Music, Research, Art and Literature. We believe that a larger sample of titles would produce a clearer picture of what constitutes the core, on the one hand, and the periphery on other hand.

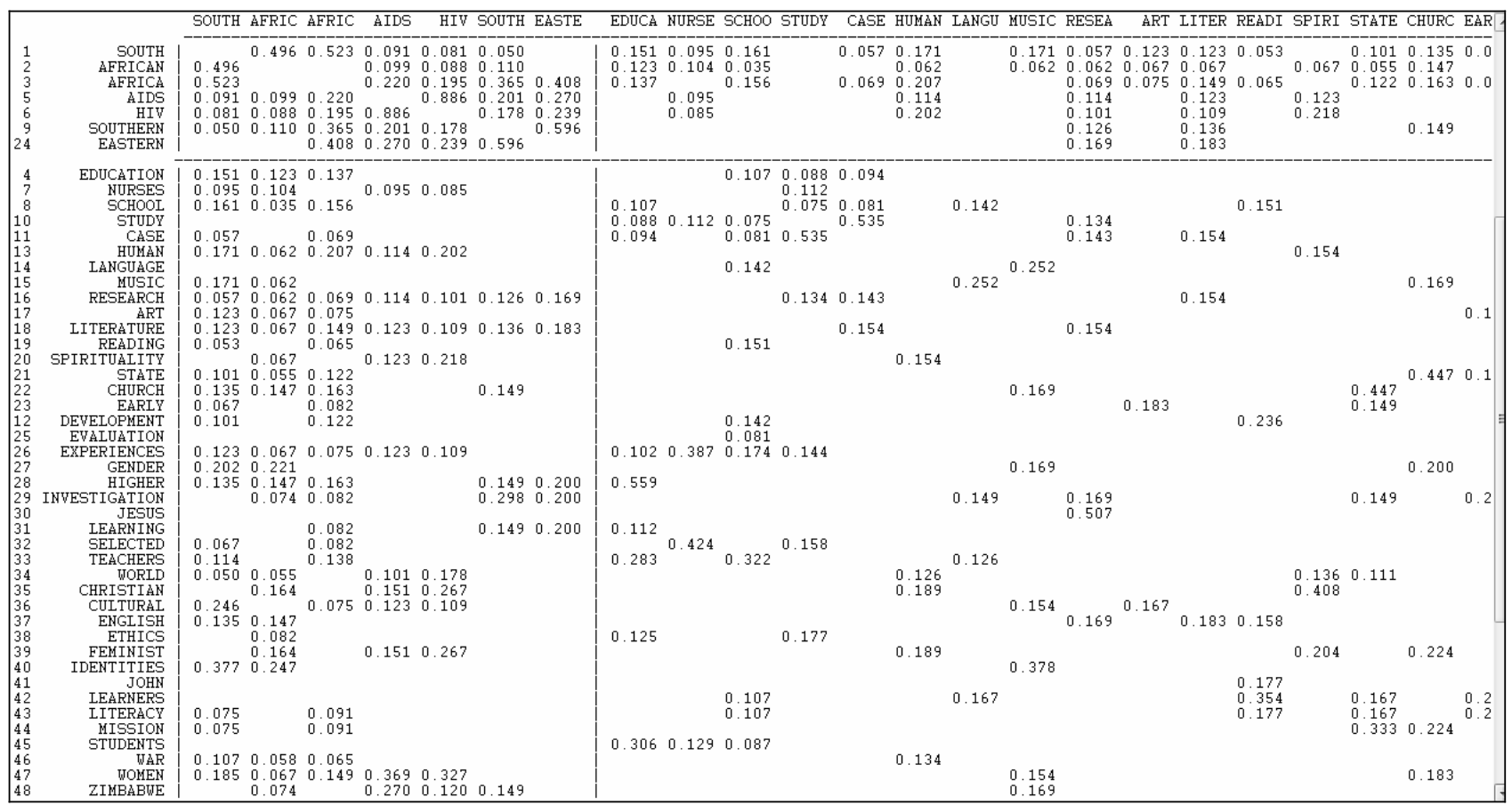

Figure 1 Core/periphery model of the most common title words

4.4 Social map of most commonly used title words

Social networks are normally used to reveal relationships amongst participating individuals, words, organisations or even countries (Onyancha, 2008). The 'words' can be contained within the full text of a document; between different documents; publication titles (see Onyancha \& Ocholla, 2009), abstracts or subject terms (Onyancha \& Ocholla, 2009b). As mentioned in the methodology section, two or more words are assumed to have a relationship if they co-occur in a document or in the case of this study, a given title. Their relationship is depicted by the line that joins them in Figure 2. The more frequently two or three words appear in different titles, the stronger their relationship, which is demonstrated by thicker lines in Figure 2.

Figure 2, which is derived from Figure I, reveals different relationships among the most common title words of the CHS publications of 2008. Stronger relationships were observed between Christian and Spirituality; Feminist and Christian; Jesus and Research; Identities and Research; World and Evaluation; Nurses and Students; HIV and Women; Higher and Education; Learning and Study; Students and Experiences; HIV and AIDS; and South and Africa, among others. It, therefore, follows that research in the College focused more on the aforementioned areas and was limited to the South African context (see also Table 4). 


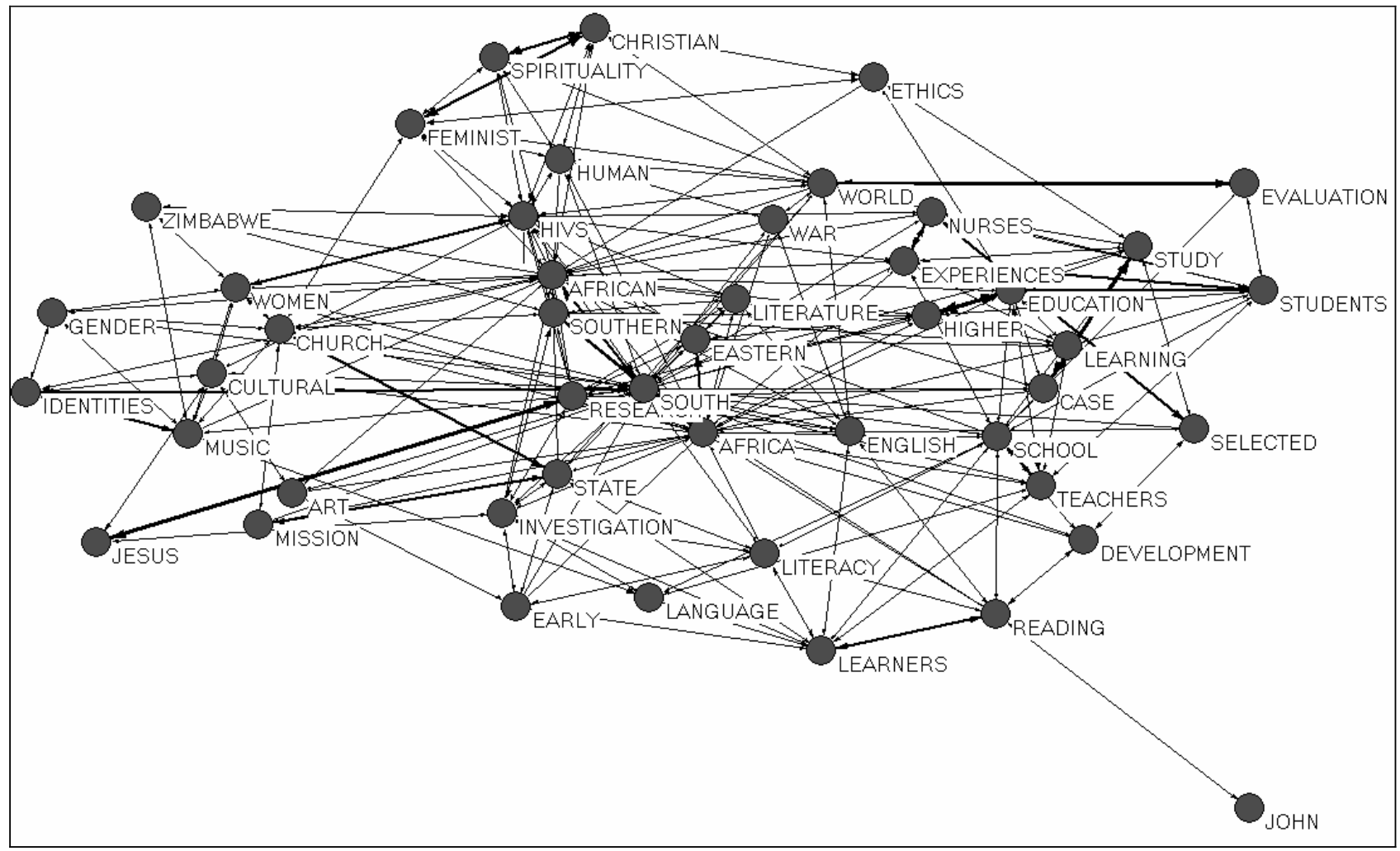

Figure 2 Social network of the most commonly used title terms

\subsection{Research collaboration at the CHS}

Research collaboration is commonly measured by co-authorship of publications (Katz \& Martin, 1997; Onyancha and Ocholla, 2007; Onyancha, 2009). Several studies have employed this technique to measure research collaboration in different countries and/or institutions (e.g. Hartinah, Davis, Hydari \& Kent, 200I:227; Lewison \& Must, 200I; and Narvaez-Berthelemot, Russell, Arvanitis, Waast \& Gaillard, 200I:470). Some of the approaches of measuring research collaboration include determining (a) the number of papers that are single- and/or co-authored; (b) the number of papers that are authored by $x$ number of authors each; (c) the number of the co-authored papers as a ratio of the total number of papers published by a given entity (author, institution and country) over a given period of time - commonly referred to as the collaboration coefficient (Onyancha, 2009).

Table 5 provides the number of publications that were authored by $\mathrm{x}$ number of authors as well as the collaboration coefficient for each department within the CHS. One-author papers were the majority and totaled 187 followed by twoauthor papers (66), three-author papers (29), and four-author papers (12) while five- and six-author papers were one (I) each. The highest number of authors who co-authored a single paper in the CHS was 6 . The paper originated in the department of History. It follows therefore that the Department of History yielded the highest number of researchers who were engaged in a single research project in 2008. However, this number is small compared to the number of coresearchers that engage in research collaboration in pure or natural sciences. For instance, in his study of the partnerships in HIV/AIDS research in sub-Saharan Africa, Onyancha (2009) found that the number of authors that were engaged in copublication of HIV/AIDS research in Eastern and Southern Africa between 198I and 2005 ranged between 2 and 202 authors in a single paper.

An examination of the collaboration coefficient reveals that the Department of Sociology's publications were all coauthored, thereby yielding a coefficient of 1.00 followed by the departments of Health Studies (0.95), Information Science (0.78), Teacher Education (0.74), Archaeology (0.69), Psychology (0.67), Linguistics (0.58), African Languages (0.55), Educational Studies $(0.50)$ and Social Work $(0.50)$, just to name those with average degree of collaboration. The other departments produced a collaboration coefficient of less than 0.5 each.

Inkanyiso, Jnl Hum \& Soc Sci 2010, 2(2) 
Table 5 Single- versus co-authored papers

\begin{tabular}{|c|c|c|c|c|c|c|c|c|c|}
\hline \multirow[t]{2}{*}{ Department } & \multicolumn{6}{|c|}{ Number of publications per $x$ number of authors } & \multirow[t]{2}{*}{ Total } & \multirow[t]{2}{*}{ No. of co-authored items } & \multirow[t]{2}{*}{ Collaboration coefficient } \\
\hline & 1 & 2 & 3 & 4 & 5 & 6 & & & \\
\hline Sociology & & 3 & & & & & 3 & 3 & 1.00 \\
\hline Health studies & 1 & 4 & 15 & & & & 20 & 19 & 0.95 \\
\hline Information science & 2 & 6 & & 1 & & & 9 & 7 & 0.78 \\
\hline Teacher education & 5 & 8 & 3 & 3 & & & 19 & 14 & 0.74 \\
\hline Archaeology & 4 & 5 & 2 & 2 & & & 13 & 9 & 0.69 \\
\hline Psychology & 3 & 3 & 1 & 1 & 1 & & 9 & 6 & 0.67 \\
\hline Linguistics & 5 & 6 & & 1 & & & 12 & 7 & 0.58 \\
\hline African languages & 5 & 4 & 1 & 1 & & & 11 & 6 & 0.55 \\
\hline Educational studies & 9 & 4 & 3 & 2 & & & 18 & 9 & 0.50 \\
\hline Social work & 1 & 1 & & & & & 2 & 1 & 0.50 \\
\hline Graduate studies & 8 & 3 & 1 & 1 & & & 13 & 5 & 0.38 \\
\hline English studies & 16 & 7 & 1 & & & & 24 & 8 & 0.33 \\
\hline Philosophy & 5 & 2 & & & & & 7 & 2 & 0.29 \\
\hline History & 7 & & $\mathrm{I}$ & & & 1 & 9 & 2 & 0.22 \\
\hline Christian spirituality & 24 & 6 & & & & & 30 & 6 & 0.20 \\
\hline Systematic theology & 5 & 1 & & & & & 6 & 1 & 0.17 \\
\hline Music \& Art & 10 & 1 & & & & & 11 & 1 & 0.09 \\
\hline Communication science & 12 & & $\mathrm{I}$ & & & & 13 & 1 & 0.08 \\
\hline New Testament & 18 & 1 & & & & & 19 & 1 & 0.05 \\
\hline Old Testament & 22 & 1 & & & & & 23 & 1 & 0.04 \\
\hline Classics & 8 & & & & & & 8 & 0 & 0.00 \\
\hline Development studies & 1 & & & & & & 1 & 0 & 0.00 \\
\hline Human sciences & 5 & & & & & & 5 & 0 & 0.00 \\
\hline Political science & 4 & & & & & & 4 & 0 & 0.00 \\
\hline Religious studies \& Arabic & 5 & & & & & & 5 & 0 & 0.00 \\
\hline School of Arts & 1 & & & & & & 1 & 0 & 0.00 \\
\hline School of humanities & 1 & & & & & & 1 & 0 & 0.00 \\
\hline Total & 187 & 66 & 29 & 12 & I & I & 296 & 109 & 0.37 \\
\hline
\end{tabular}

Single- and multiple-author publications

A total of 187 (63.18\%) papers were singly authored while 109 (36.82\%) were each co-authored by between 2 and 6 authors. This pattern of authorship reveals a higher degree of individual research as opposed to collaborative research in the CHS. 
Table 6 Internal and external co-authorship of publications in the CHS, 2008

\begin{tabular}{|c|c|c|c|c|c|}
\hline Department & Internal collaboration & External collaboration & Total & $\%$ Internal collaboration & \% external collaboration \\
\hline Health studies & 6 & 13 & 19 & 31.58 & 68.42 \\
\hline Teacher education & 8 & 6 & 14 & 57.14 & 42.86 \\
\hline Archaeology & 0 & 9 & 9 & 0.00 & 100.00 \\
\hline Educational studies & 4 & 5 & 9 & 44.44 & 55.56 \\
\hline English studies & 3 & 5 & 8 & 37.50 & 62.50 \\
\hline Information science & 3 & 4 & 7 & 42.86 & 57.14 \\
\hline Linguistics & 4 & 3 & 7 & 57.14 & 42.86 \\
\hline African languages & 2 & 4 & 6 & 33.33 & 66.67 \\
\hline Christian spirituality & 6 & 0 & 6 & 100.00 & 0.00 \\
\hline Psychology & 3 & 3 & 6 & 50.00 & 50.00 \\
\hline Graduate studies & I & 4 & 5 & 20.00 & 80.00 \\
\hline Sociology & I & 2 & 3 & 33.33 & 66.67 \\
\hline History & I & I & 2 & 50.00 & 50.00 \\
\hline Philosophy & 2 & 0 & 2 & 100.00 & 0.00 \\
\hline Communication science & 0 & I & 1 & 0.00 & 100.00 \\
\hline Music \& Art & 0 & I & 1 & 0.00 & 100.00 \\
\hline New Testament & I & 0 & 1 & 100.00 & 0.00 \\
\hline Old Testament & 0 & I & 1 & 0.00 & 100.00 \\
\hline Social work & 0 & I & 1 & 0.00 & 100.00 \\
\hline Systematic theology & I & 0 & 1 & 100.00 & 0.00 \\
\hline Classics & 0 & 0 & 0 & 0.00 & 0.00 \\
\hline Development studies & 0 & 0 & 0 & 0.00 & 0.00 \\
\hline Human sciences & 0 & 0 & 0 & 0.00 & 0.00 \\
\hline Political science & 0 & 0 & 0 & 0.00 & 0.00 \\
\hline Religious studies \& Arabic & 0 & 0 & 0 & 0.00 & 0.00 \\
\hline School of Arts & 0 & 0 & 0 & 0.00 & 0.00 \\
\hline School of humanities & 0 & 0 & 0 & 0.00 & 0.00 \\
\hline TOTAL & 46 & 63 & 109 & 42.20 & 57.80 \\
\hline
\end{tabular}

Internal and external collaboration

An analysis of internal and external ${ }^{3}$ collaboration shows that the latter was the predominant practice among the $\mathrm{CHS}$ researchers with a total of 5 departments recording $100 \%$ external collaboration (i.e. collaboration with authors from outside UNISA). These departments include: Archaeology, Communication Science, Music \& Art, Old Testament and Social Work. It should however be noted that, apart from the Department of Archaeology which produced a total of 9 publications that were published with external authors, the rest of the departments produced only one co-authored article each, a situation that may not provide accurate comparison of external collaboration in research between the College's staff and those from outside UNISA. With regard to the internally co-authored publications, only 4 departments recorded a collaboration coefficient of 0.5 and above (i.e. $\pm 50 \%$ of co-authored papers), implying that the majority of the departments witnessed little or no internal collaboration where internal collaboration refers to authorship of publications between two or more authors working at UNISA. It is a general observation that more than one half (i.e. 1/2)

3. External collaboration refers to a situation where a researcher at UNISA partners with a researcher from another institution to conduct joint research. 
of the co-authored papers originated from external collaboration. It was not however possible to determine the type of external collaboration. For instance, it was not possible to answer such questions as: is the collaboration between students (whose institutional affiliation is not UNISA) and UNISA staff? Is the collaboration between academics belonging to other universities and their peers at UNISA? Are UNISA's external collaborators from the industry or the education sector? Are the collaborators from foreign or regional (i.e. African) countries? This aspect is worth investigating as UNISA strives to become an African University in service of humanity.

\section{Conclusion and recommendations}

Although the findings on the College of Human Sciences' research output for 2008 is not sufficient to generalise the performance of the college as far as research is concerned as well as draw and offer informed conclusions and valid recommendations, respectively, it has been observed that during 2008 ,

- The college produced fewer research outputs than expected. Whereas the expected research output from the teaching staff only was 476.4, the CHS's actual research output was only 300.44 . It should, however, be noted that the actual figure comprised publications that met the DoE's requirements for subsidy. Publications that do not meet the DoE requirements were not considered for analysis in this study. This implies that the actual output could have been higher.

- Research at the college is largely focused on HIV/AIDS and contextualised within South, Southern and/or Eastern Africa.

- A mere 4 out of 27 (i.e. 14.8\%) departments and institutes (i.e. Christian Spirituality, English Studies, Old Testament, and New Testament) within the college produced approximately one-third $(1 / 3)$ of the total number of the college's publications.

- Single authored publications are in the majority when compared to co-authored publications.

- Departments or institutes that performed well in terms of the total research output (e.g. Christian Spirituality, Music \& Art, Communication Science, New Testament and Old Testament) exhibited minimal research collaboration as witnessed in their collaboration coefficient.

- External collaboration is the predominant practice at the college when compared to internal collaboration.

This article further demonstrates the relevance of informetrics, as a research method, in evaluating institutional (in this case, university) research. The article focused on mapping subject or topics of research focus as well as research collaboration in the CHS. Other areas that can be assessed in research evaluation include the most productive authors; the most commonly used journals in which the research of a given institution is published; the citation count and citation impact of research produced in a given institution; patents registered by authors; the relationship between conference attendance and article publication by individual authors; research output by Masters and Doctoral students; the relationship between the registration of research projects within the college or faculty and research articles in accredited journals; and a review of SAPSE accredited publications against those published in non-SAPSE accredited journals (see Ocholla and Mostert. 2010).

Further areas of research are recommended in the following respects:

- Citation analysis of the CHS's research

- Expand the scope of records to include those published before and after 2008

- An analysis of the non-SAPSE accredited publications

- Comparison of CHS's research output with other colleges' output

\section{Acknowledgements}

This report was commissioned by Dr. Britta Zawada, Director of the School of Arts. I would like to acknowledge assistance offered by various individuals (e.g. the Research Directorate, the ICT department, and the Dean of the College of Human Sciences' office) in the preparation of this report.

\section{References}

Borgatti, S.P. and Everett, M.G. 1999. Models of core/periphery structures. Social Networks 21:375-395.

Borgatti, S.P. Everett, M.G. and Freeman, L.C. 2002. Ucinet 6 for Windows. Harvard: Analytic Technologies.

Hartinah, S., Davis, M., Hydari, A., \& Kent, P. 200I. Indonesian nutrition research papers 1979-98: A bibliometric analysis. In: M Davis \& C. S. Wilson (eds.). Proceedings of the 8th International Conference on Scientometrics and Informetrics, Sydney, July, 1620, I, 225-177.

Hertzel, D. 1987. Bibliometrics, history of the development of ideas in: Statistical bibliography or bibliometrics? In: A Kent \& H. Lancour (Eds). Encyclopaedia of Library and Information Science, 42, I44-219. 
Jacobs, D. 2002. Scientometrics of genetic research and development in South Africa, 1990-200I. In: T. Bothma \& A. Kaniki eds. Progress in Library and Information Science in Southern Africa: proceedings of the second biennial DISSAnet conference, $93-103$. Glenstantia: Infuse

Katz, J.S. \& Martin, B.R. (1997). What is research collaboration? Research policy, 26(I), I- I8.

King, J. 1987. A review of bibliometric and other science indicators and their role in research evaluation. Journal of Information Science, 13, 26|-276.

Kizito, M. 2002. The importance of content analysis in HIV/AIDS reporting. Paper presented at a UNESCO sub-regional training workshop on legal and ethical issues in HIV/AIDS reporting for the media women, 5-8 March 2002, Nairobi, Kenya. http:// aids-africa.unon.org/events/Dr\%20Kizitos.doc (Accessed I 2 January 2009).

Konforti, B. 200I. Twenty years ago. Nature Structural Biology, 8(7), 582.

Kostoff, R. N. 200I. Science and Technology Metrics. [Online]. Defence Technical Information Center. Information for the Defence Community Website http://www.dtic.mil/dtic/kostoff/Metweb5_IV.htm (Accessed I 2 January 20I0).

Lewison, G., \& Must, U. 200I. Estonian international cooperation in science in the 1990s: New politics, new methods. In: M. Davis \& C. S. Wilson (eds.). Proceedings of the 8th International Conference on Scientometrics and Informetrics, Sydney, July, I620, 2, 385-395

Macias-Chapula, CA, Sotolongo-Aguilar, G. R., Magde, B. \& Solorio-Lagunas, J. 1999. Subject analysis of AIDS literature, as produced in Latin America and the Caribbean. Scientometrics 46(3):563-574.

Narvaez-Berthelemot, N., Russell, J. M., Arvanitis, R., Waast, R., \& Gaillard, J. 200I. Science in Africa: An overview of mainstream scientific output. In: M. Davis \& C. S. Wilson (eds.). Proceedings of the 8th International Conference on Scientometrics and Informetrics, Sydney, July, I6-20, 2, 469-476

Nicholas, D. \& Ritchie, M. 1978. Literature and bibliometrics. London: Clive Bingley.

Ocholla, D.N. \& Mostert, J.B. 20I0. The research trends of Arts, Humanities and Social Sciences Research at the University of Zululand, 1994 - 2008. Inkanyiso: Journal of Humanities and Social Science, 2(I): 32-43.

Onyancha, O.B. 2008a. Authorship patterns of the literature on HIV/AIDS in Eastern and Southern Africa: an exposition of the responsible authors, institutions and countries, 1980-2005. South African Journal of Libraries and Information Science, 74(I): 922.

Onyancha, O.B. Changing patterns and trends in author co-authorship networks of HIV/AIDS research in Eastern and Southern Africa. Mousaion, 26(2): 59-78.

Onyancha, O.B. 2009. Towards global partnerships in research in Sub-Saharan Africa: an informetric study of the national, regional and international country collaboration in HIV/AIDS literature in eastern and southern Africa. South African Journal of Libraries and Information Science, 75(I): 84-97

Onyancha, O.B. \& Ocholla, D.N. 2007. Country-wise collaborations in HIV/AIDS research in Kenya and South Africa, 19802005. LIBRI, 57(4): 239-254.

Onyancha, O.B. \& Ocholla, D.N. 2009. Is HIV/AIDS in Africa distinct? What can we learn from an analysis of the literature? Scientometrics, 79(I):277-296.

Onyancha, O.B. \& Ocholla, D.N. 2009b. Conceptualizing 'knowledge management' in the context of library and information science. South African Journal of Information Management, I I(4):I-I5. Available online at: http://www.sajim.co.za/index.php/ SAJIM/article/view/4 I 2/402.

Republic of South Africa. Ministry of Education. 2003. Policy and procedures for measurement of research output of public higher education institutions. [Pretoria]: Ministry of Education.

Russell, J.M. \& Rousseau, R. (not dated). Bibliometrics and institutional evaluation. http://www.vub.ac.be/BIBLIO/itp/lecturers/ ronald_rousseau/ronald_roussea_stim I_bibliometrics_russell.pdf (Accessed 27 July 2010).

Sengupta, I. N. 1992. Bibliometrics, informetrics, scientometrics and librametrics: An overview. Libri, 42(2), 75-98

UNISA. 2006. Research policy. Pretoria: UNISA. [Online]. Available at: http://www.unisa.ac.za/cmsys/staff/contents/departments/ res_policies/docs/Research_Policy_26apr06.pdf(Accessed I5 April 2010).

UNISA. 20I0. Institutional Ōperational Plan (IOP). Pretoria: UNISA. [Online]. Available at: http://www.unisa.ac.za/cmsys/staffI contents/e-notice2010/january/docs/IOPI4012010.pdf (Accessed I2 May 2010)

Victoria, U. n.d. Introduction to Informetrics. http://kmi.open.ac.uk/people/victoria/Informetrics.htm (Accessed 4 August 2008). 